\title{
Design of Symmetric Magnetic Lenses with Optimum Operational Conditions
}

\author{
Basma Faiz Abd Alghane and Ahmad K. Ahmad* \\ Department of Physics, College of Science, Al-Nahrain University, Jadriayh, P.O.Box 64055, Baghdad, Iraq
}

\begin{tabular}{|c|c|}
\hline Article's Information & Abstract \\
\hline $\begin{array}{l}\text { Received: } \\
06.11 .2020 \\
\text { Accepted: } \\
\text { 24.01.2021 } \\
\text { Published: } \\
\text { 13.03.2021 }\end{array}$ & $\begin{array}{l}\text { In the present paper, the geometrical and optical object properties of } \\
\text { symmetrical magnetic lens are designed and analyzed using the electron optical } \\
\text { design (EOD) program. The effect of the axial aperture diameter (D), the air gap } \\
\text { between the poles (s), the thickness of the poles (t), the excitation parameter NI } \\
\text { of the lens are all studied for the best optical properties like the object focal } \\
\text { length fo, the spherical and chromatic aberrations coefficients ( } \mathrm{C}_{\mathrm{s}} \text { and } \mathrm{C}_{\mathrm{c}} \\
\text { respectively). It was found that the optical properties of the object significantly }\end{array}$ \\
\hline $\begin{array}{l}\text { Keywords: } \\
\text { Magnetic lens } \\
\text { EOD program } \\
\text { Spherical } \\
\text { Chromatic aberration coefficients }\end{array}$ & $\begin{array}{l}\text { improved with a decrease in the axial aperture diameter and width of the air } \\
\text { gap of this lens. } \\
\text { Upon our study, it was found that the best properties are achieved when the } \\
\text { air gap width }(\mathrm{S}=2 \mathrm{~mm}) \text {, and the axial hole diameter }(\mathrm{D}=6 \mathrm{~mm}) \text {. The effect of the } \\
\text { electrode face thickness on the magnetic properties of the proposed magnetic } \\
\text { lens is studied, it was found that the best magnetic properties and the highest } \\
\text { value of magnetic flux and the lowest value of the axial magnetic field strength } \\
\text { bandwidth were at electrode face thickness equal to ( } 3 \text { and } 4 \mathrm{~mm}) \text {. Therefore, } \\
\text { the best magnetic lens in our design with the best optical properties was } \mathrm{S}=2 \\
\mathrm{~mm}, \mathrm{D}=6 \mathrm{~mm} \text { and } \mathrm{t}=3 \mathrm{~mm} \text {. }\end{array}$ \\
\hline
\end{tabular}

DOI: 10.22401/ANJS.24.1.06

*Corresponding author: ahmad.ahmad@ced.nahrainuniv.edu.iq (Orcid ID: 0000-0003-3522-4701)

\section{Introduction}

Magnetic lenses are extremely important in many scientific and industrial application like in, scanning and transmission electronic microscopes (SEM and TEM respectively) [1, 2], electron and ion beam lithography systems [3, 4], ion implantation system [3], accelerators [4] and many electron and ion beam emitted focusing systems [5]. If the performance of this lens is not good and not at the appropriate level, an accurate electronic sensor cannot be produced. The best geometry of the lens shaft, operating conditions (amount of excitation, acceleration voltage, operating mode and the required object properties), as well as, the suitable shape and size of the coil [3]. In order to design magnetic lenses, they need to be decided.

Al-Khashab and Ahmed, in 2004, had several approaches to the geometry of the pole piece of the magnetic projector lens and its effect on flux lines, her work concerns on the optical properties of the magnetic projector lenses of double and single pole [6]. In 2004, Alamir, had investigated the chromatic aberration of magnetic lenses with field distribution in the form of inverse law analytical methods [7]. Study of the effect of the position and geometry of the coil on the magnetic flux lines and on the shape of flux density distribution by designing and studying the local properties of the magnetic lens by Alaa Ahmed [8]. The magnetization of the single pole piece magnetic electron lens using different coil models by Al-Abdullah and Al-Khashabin 2006, they have been found that the selection of the proper type of the coil geometry to improves the performance of the magnetic single pole piece lens for equal value of the current density [9]. In 2009 Chalab, a theoretical computational study was conducted to explain the optimal optimization of symmetric double-pole magnetic lenses in the absence of analytical magnetic saturation by studying the variance of the parameters of the air gap width (S), the axial bore diameter (D) and the lens excitation (NI) of the conical spherical and conical magnetic lenses with the two tapered pieces [10]. In 2010, the design of objective magnetic and electrostatic lenses with low aberration coefficients was of considerable interest to Al-Khashab and Hujazie [11]. In 2012, Al-Batat and Al-Rubaye, performed a theoretical study using synthesis method optimization to simulate and design the symmetrical double pole piece magnetic electron lens. The objective focal properties of the double pole piece magnetic lenses with respect to the image space have been studied under the effect of the field parameters [12]. In 2013 Ahmed, had study two types of electron lenses (magnetic and electrostatic) in order to obtain the preferable configuration of a compound lens, he was found that the lens with iron insulation has been achieved better optical performance [13]. In 2014, Hujazie and Hussain, conducted a detailed analysis on the optical efficiency of the magnetic condenser dual lens system to obtain the best condenser lens configuration in the scanning electron 


\title{
Al-Nahrain Journal of Science
}

\author{
ANJS, Vol.24 (1), March, 2021, pp. 30-38
}

microscope, where four models of magnetic lenses were designed with different dimensions and a different pole shapes [14]. In 2015, Abdulla gives attention on the impact of current density and lens dimensions on the design of iron-free magnetic lenses. A magnetic field has been measured for various values of current density. Also, the radial and spiral distortion aberration coefficients have been computed [15]. El-Shahat et al., they explore the objective properties of a single pole piece magnetic lens with various shapes of pole parts where the results indicate that the lens with a spherical pole-face has the best resolution. [16]. Abbas and Sahi in 2017, study the objective focal properties of a symmetrical double pole piece style magnetic electron lenses using the EOD program [17]. In 2018 Numan, presented some of the lens's critical geometric characteristics, such as bore diameter, air gap length, half width, magnetic flux density, focal length of the projector, focusing power, magnification, and spherical aberration. The effective length, half-half width, and the minimum projector focal length increased the slope when the air gap width and the diameter of the lens are growing. The increase in the bore and air gap width of lens resulted in an exponential decreasing in the magnetic flux density. The increase of ampere-turns resulted in a linear increase in the magnetic flux density. Finally, the increasing in the air gap length and the diameter of the lens caused a ramp increase in the spherical aberration coefficient [18]. In 2019, two versions of asymmetrical magnetic objective lens geometries were modeled and researched by Marwa Al-Shamma, these two versions are known as Pinhole and Snorkel [19].

In present work a design of symmetrical magnetic lens under different geometrical design parameter for the best optical properties and performance using the EOD program.

\section{Design of Symmetrical Magnetic Lens}

The Electron Optical Design (EOD) software [20] are used in the present work. The program is based on the finite element method (FEM) as it determines the dimensions of the magnetic lens and distributes the mesh lines to it for the purpose of measuring the axial magnetic flux and its optical properties oriented towards the target. Figure 1(a) shows a cross-section of the upper half of the proposed magnetic lens built in this study, as the geometric measurements of this proposed lens show the axial length $(\mathrm{L}=70 \mathrm{~mm})$ and the radial width $\left(\mathrm{W}_{\mathrm{r}}=86 \mathrm{~mm}\right)$ and this lens has a circular coil number of turns $(\mathrm{N}=500$ turn) and a cross-section area of $\left(\mathrm{A}=748 \mathrm{~mm}^{2}\right)$. The coil axis penetrates two wrought iron magnetic poles wit. The axial magnetic field $\left(B_{z}\right)$ collects as a constant electrical current (I) passes through the circular coil, and the coil and the two electrodes are surrounded by a circle of wrought iron to prevent the magnetic field from leaking out of the lens. The lens was turned on at a value of (NI=4000 A. t.) by excitation of the coil and thus the current density was measured at a value of $\left(\sigma=5.34759 \mathrm{~A} / \mathrm{mm}^{2}\right)$. A 3D design of the symmetric magnetic lens is shown in Figure 1(b).
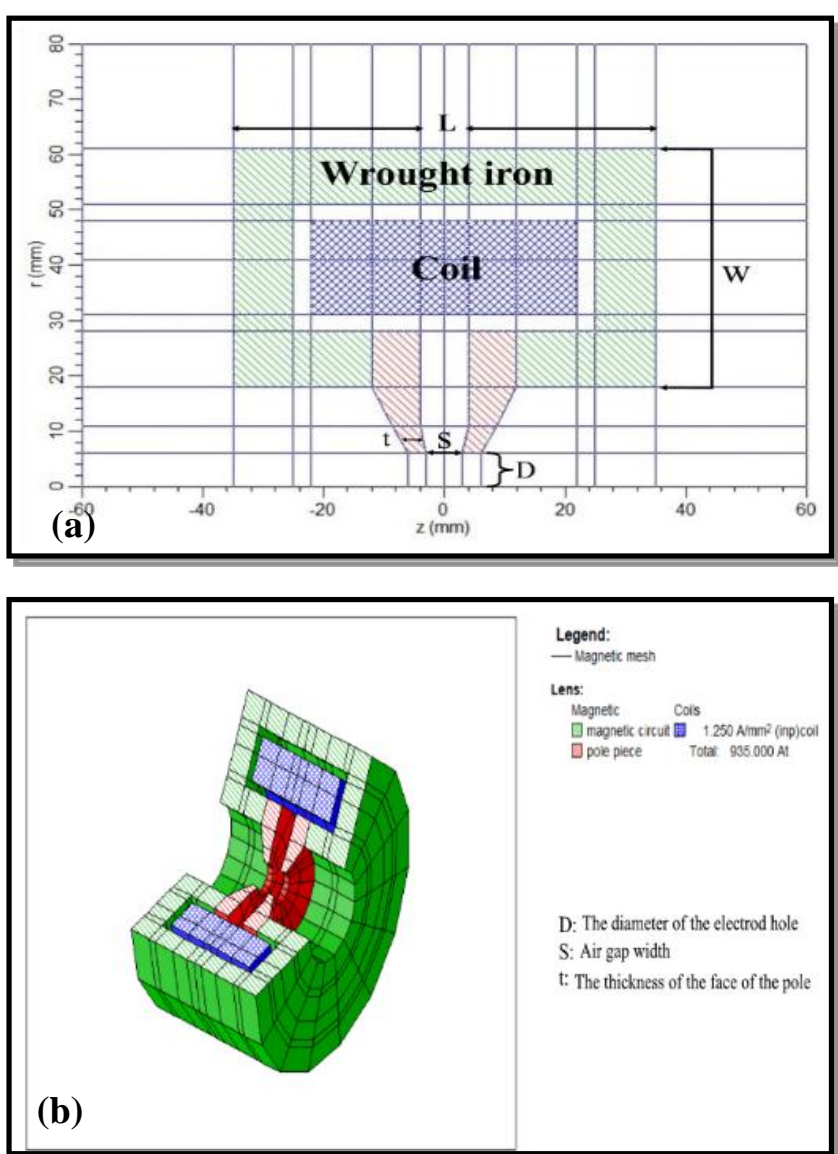

Figure 1. (a) The upper half of the proposed symmetrical magnetic lens cross-section (b) The proposed 3D Symmetrical magnetic lens.

\section{Results and Discussion}

\subsection{The effect of the diameter of the axial aperture (D) on the objective properties of the magnetic lens}

Different values of the diameter of the axial aperture of the lens (D) which are ( $D=2,4,6,8,10,12$ and $14 \mathrm{~mm})$ have been used to study the effect of the diameter of the axial aperture of the lens (D) on the axial magnetic field $B_{z}$ and the path of the electron beam and thus on the optical properties of the magnetic lens.

The axial magnetic flux density distributions $\mathrm{B}(\mathrm{z})$ are shown in Figure 2 for symmetrical magnetic lenses along the optical axis ( $\mathrm{z}$ ), for different values of the axial aperture diameter $(\mathrm{D}=2,4,6,8,10,12$ and $14 \mathrm{~mm})$, at constant air gap value $(\mathrm{S}=6 \mathrm{~mm})$. As shown in Figure 3, the diameter of the axial hole (D) induces a decrease in the maximum value of magnetic flux density $\left(B_{\max }\right)$ and an increase in the half-field width (W) values. This is explained by the fact that raising the axial aperture diameter leads to a rise in the region where the magnetic field spreads through the lens poles. The lens poles 


\section{Al-Nahrain Journal of Science}

ANJS, Vol.24 (1), March, 2021, pp. 30-38

decrease the value of the magnetic field centered between the poles in the air gap.

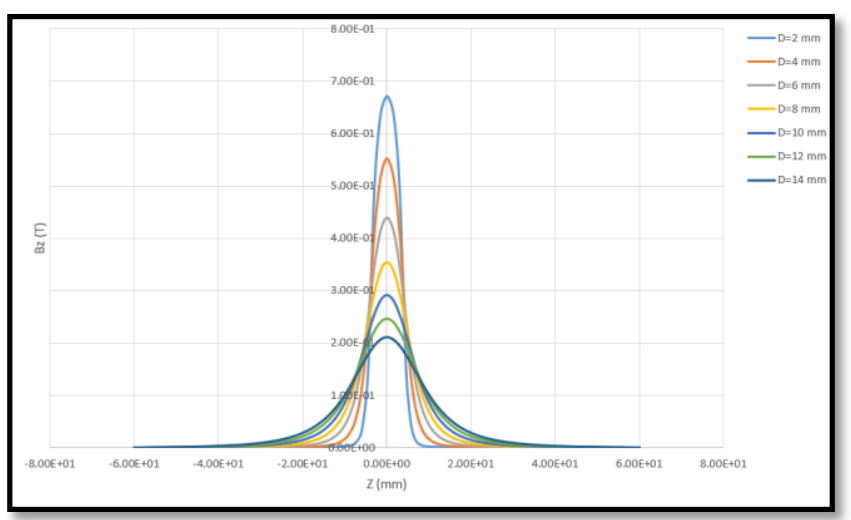

Figure 2. The distribution curves of the axial magnetic flux density $\left(B_{z}\right)$ at variable values of $D$.

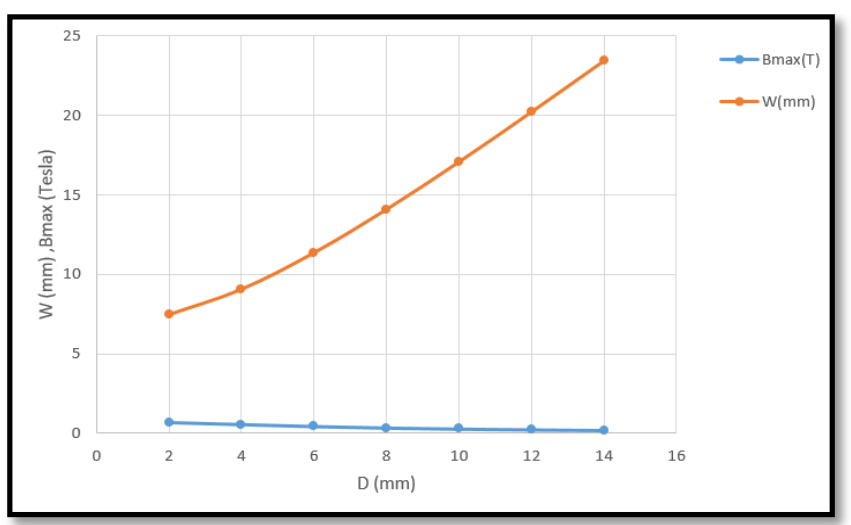

Figure 3. The Variance of the maximum magnetic flux density $\left(\mathrm{B}_{\max }\right)$ and the half-field $(\mathrm{W})$ with the axial aperture diameter of the magnetic lens poles (D).

The change in the maximum magnetic flux density $\left(B_{\max }\right)$ indicating different excitation parameter values of the proposed lens shown in Figure 4, where the increase in the maximum magnetic flux density values is noted with increasing the excitation parameter at a fixed voltage of $(\mathrm{Vr}=5000 \mathrm{~V})$ and with the remaining constant parameters.

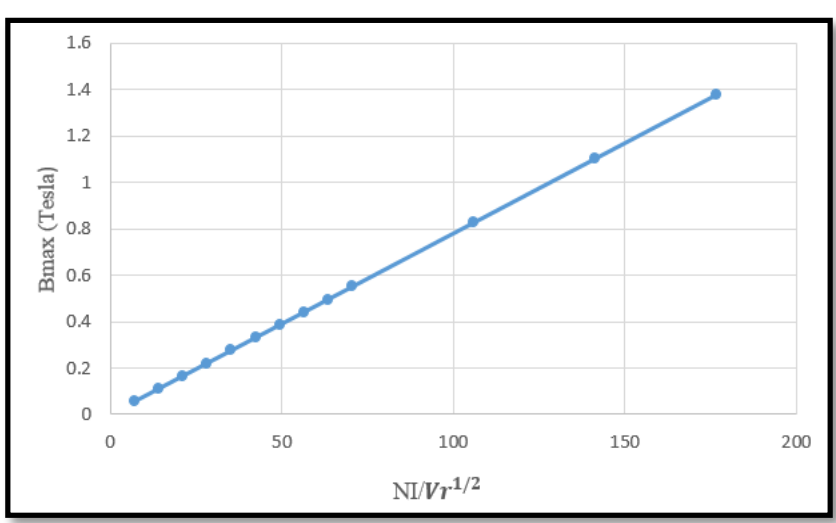

Figure 4. Displays the change in the maximum magnetic flux density $\left(\mathrm{B}_{\max }\right)$ for the proposed lens for different excitation parameter $\left(\mathrm{NI} / \mathrm{Vr}^{1 / 2}\right)$ values.
The trajectories of the electron beams of the symmetrical lens with different air gap widths are shown in Figure 5. From this figure one can see that as D is smaller the paths are closer to the optical axis.

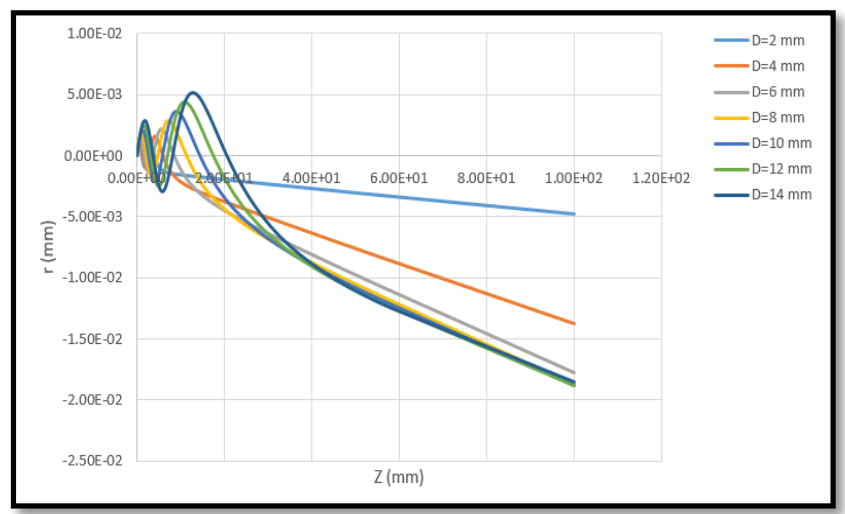

Figure 5. The trajectories of the electron beams for the proposed lens when excited are stationary $(\mathrm{NI}=4000 \mathrm{~A}-\mathrm{t})$ and for different values of D.

Figure 6 shows the values of the relative spherical and chromatic aberration coefficients as function of D. Here, the values of the aberrations are all less than 1 , which is very good values, also the values of the aberrations are decreases with increasing D.

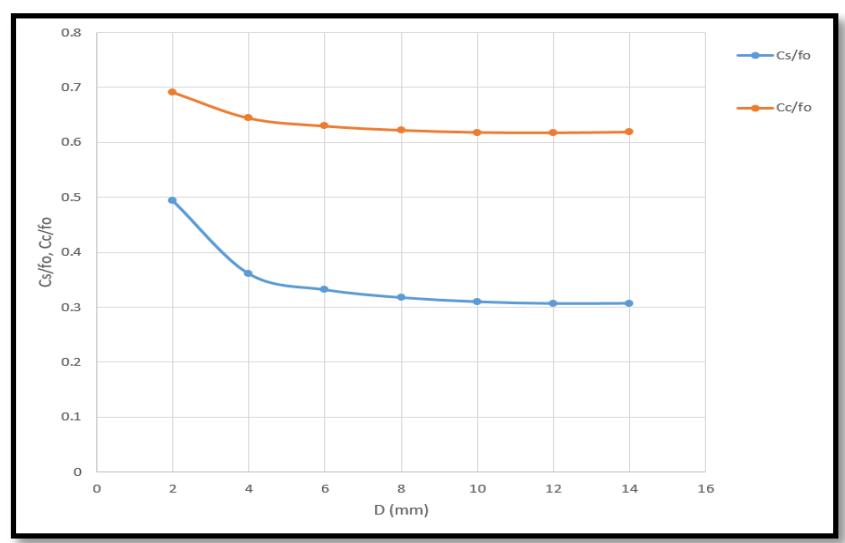

Figure 6. The relative spherical and chromatic aberrations coefficients $\left(\mathrm{C}_{\mathrm{s}} / \mathrm{f}_{\mathrm{o}}\right)$ and $\left(\mathrm{C}_{\mathrm{c}} / \mathrm{f}_{\mathrm{o}}\right)$ respectively as function of the diameter of the axial aperture (D).

Figure 7 represents the values of the relative spherical and chromatic aberration coefficients $\left(\mathrm{C}_{\mathrm{s}} / \mathrm{f}_{\mathrm{o}}\right)$ and $\left(\mathrm{C}_{\mathrm{c}} / \mathrm{f}_{\mathrm{o}}\right)$ respectively, as function of the excitation parameter $\mathrm{NI} / \mathrm{V}_{\mathrm{r}}^{1 / 2}$. From this figure one can notice that the values of $\left(\mathrm{C}_{\mathrm{s}} / \mathrm{f}_{\mathrm{o}}\right)$ and $\left(\mathrm{C}_{\mathrm{c}} / \mathrm{f}_{\mathrm{o}}\right)$ are decreasing with increasing $\mathrm{NI} / \mathrm{V}_{\mathrm{r}}^{1 / 2}$, and nearly all the values of aberration are less than one. 


\section{Al-Nahrain Journal of Science}

ANJS, Vol.24 (1), March, 2021, pp. 30-38

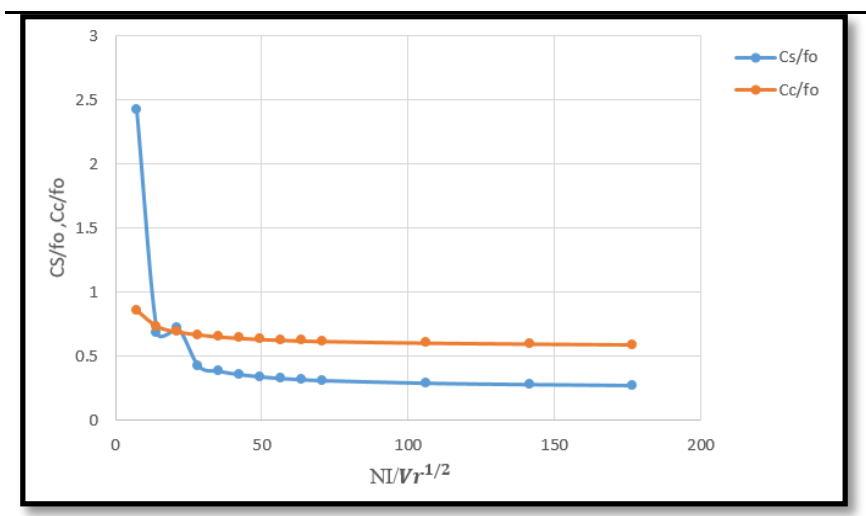

Figure 7. Show the relative spherical and chromatic aberrations coefficients $\left(\mathrm{C}_{\mathrm{s}} / \mathrm{f}_{\mathrm{o}}\right)$ and $\left(\mathrm{C}_{\mathrm{c}} / \mathrm{f}_{\mathrm{o}}\right)$ respectively as function of excitation parameter $\left(\mathrm{NI} / \mathrm{Vr}^{1 / 2}\right)$.

Figure $8(\mathrm{a} \& \mathrm{~b})$ represents the relative spherical and chromatic aberrations coefficients (a) $\mathrm{C}_{\mathrm{s}} / \mathrm{f}_{\mathrm{o}}$ and (b) $\mathrm{C}_{\mathrm{c}} / \mathrm{f}_{\mathrm{o}}$ respectively, as function a function of acceleration voltages at constant excitation ( $\mathrm{NI}=4000$ A-turn) for different values of $\mathrm{D}$. From this figure, one can say that the values of both $\mathrm{C}_{\mathrm{s}} / \mathrm{f}_{\mathrm{o}}$ and $\mathrm{C}_{\mathrm{c}} / \mathrm{f}_{\mathrm{o}}$ are good and less than one for a wide range of the values of the axial aperture diameters and a wide range of accelerating voltages, which indicates that our proposed symmetrical magnetic lens is a good design.
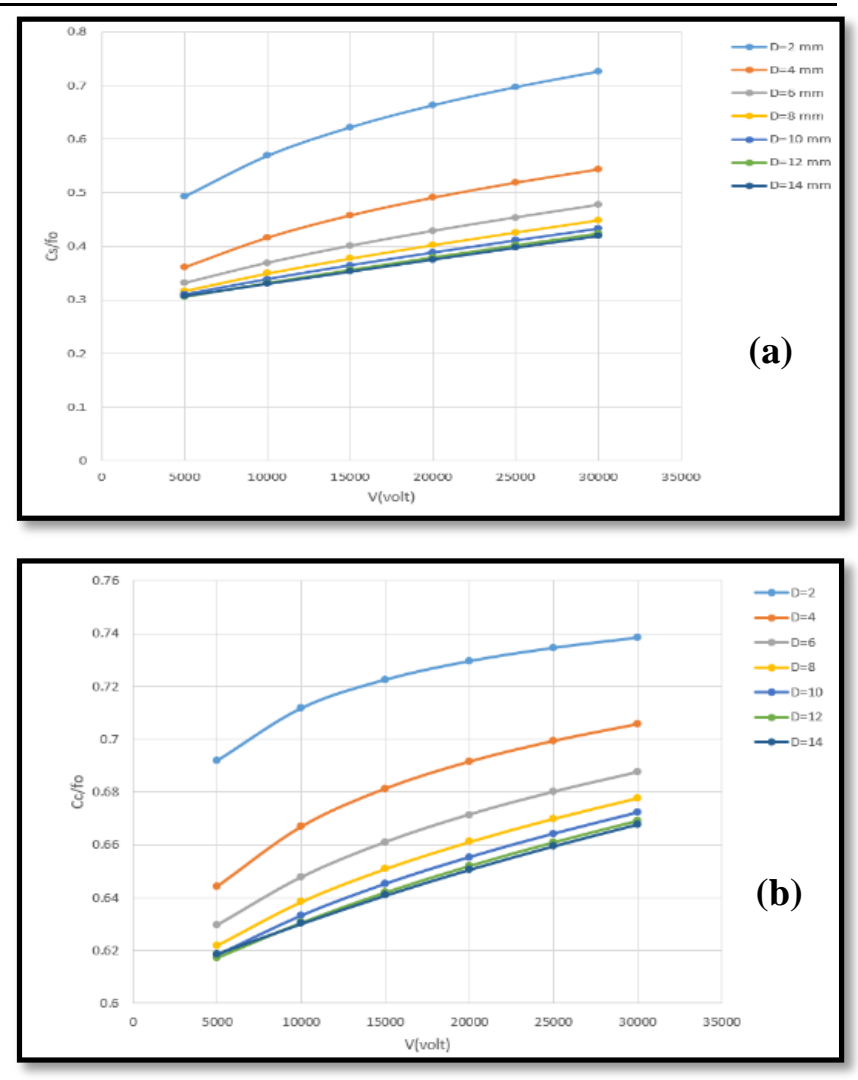

Figure 8. The relative (a) spherical aberrations coefficient $\left(\mathrm{C}_{\mathrm{s}} / \mathrm{f}_{\mathrm{o}}\right)$ and (b) and chromatic aberrations $\left(\mathrm{C}_{\mathrm{c}} / \mathrm{f}_{\mathrm{o}}\right)$, as function a function of acceleration voltages at constant excitation ( $\mathrm{NI}=4000$ A-turn) for different axial aperture diameter values (D).

Table 1, summarized the results of the spherical and chromatic aberration coefficients as function of the values of $\mathrm{D}$ and $\mathrm{f}_{\mathrm{o}}$.

Table 1. Adjusts the object-oriented optical property values to the axial aperture diameter (D).

\begin{tabular}{|c|c|c|c|c|c||}
\hline $\mathbf{D}(\mathbf{m m})$ & $\mathbf{f}_{\mathbf{o}}(\mathbf{m m})$ & $\mathbf{C}_{\mathbf{s}}(\mathbf{m m})$ & $\mathbf{C}_{\mathbf{c}}(\mathbf{m m})$ & $\mathbf{C}_{\mathbf{s}} / \mathbf{f}_{\mathbf{o}}$ & $\mathbf{C}_{\mathbf{c}} / \mathbf{f}_{\mathbf{o}}$ \\
\hline \hline 2 & 1.08299 & 0.53412 & 0.74916 & 0.49319 & 0.69175 \\
\hline 4 & 1.75997 & 0.63458 & 1.13373 & 0.36056 & 0.64417 \\
\hline 6 & 2.59401 & 0.85998 & 1.63322 & 0.33152 & 0.62961 \\
\hline 8 & 3.50502 & 1.11257 & 2.17991 & 0.31742 & 0.62193 \\
\hline 10 & 4.46889 & 1.38462 & 2.76241 & 0.30983 & 0.61814 \\
\hline 12 & 5.45364 & 1.67262 & 3.36688 & 0.30669 & 0.61736 \\
\hline 14 & 6.42621 & 1.97342 & 3.97675 & 0.30708 & 0.61883 \\
\hline
\end{tabular}

\subsection{The effect of the air gap width (S) on the objective properties of the magnetic lens}

In order to study the effect of the width of the air gap (S) on the optical performance of the symmetrical magnetic lens, different values have been chosen for the $(\mathrm{S}),[\mathrm{S}=(2$, $4,6,8,10,12,14) \mathrm{mm}]$, Other engineering parameters remain constant where $(\mathrm{D}=6 \mathrm{~mm}), \quad\left(\mathrm{V}_{\mathrm{r}}=5000\right.$ volt $)$,
$(\mathrm{NI}=4000$ A-turn). Figure 9 shows the effect of the width of the air gap on the axial magnetic flux density $\left(\mathrm{B}_{\mathrm{Z}}\right)$, one can observe that the maximum value of the magnetic flux density $\left(\mathrm{B}_{\max }\right)$ decreases with increasing the value of $\mathrm{S}$ and is accompanied by an increase in the half width as shown in the Figure 10.

From Figure 11, one can see the linear relation between the change in the maximum magnetic flux density $\left(\mathrm{B}_{\max }\right)$, 


\section{Al-Nahrain Journal of Science}

ANJS, Vol.24 (1), March, 2021, pp. 30-38

and the excitation parameters (NI) at air gap width $(\mathrm{S}=2$ $\mathrm{mm})$. This linear relationship indicates the readability of the proposed lens designed.

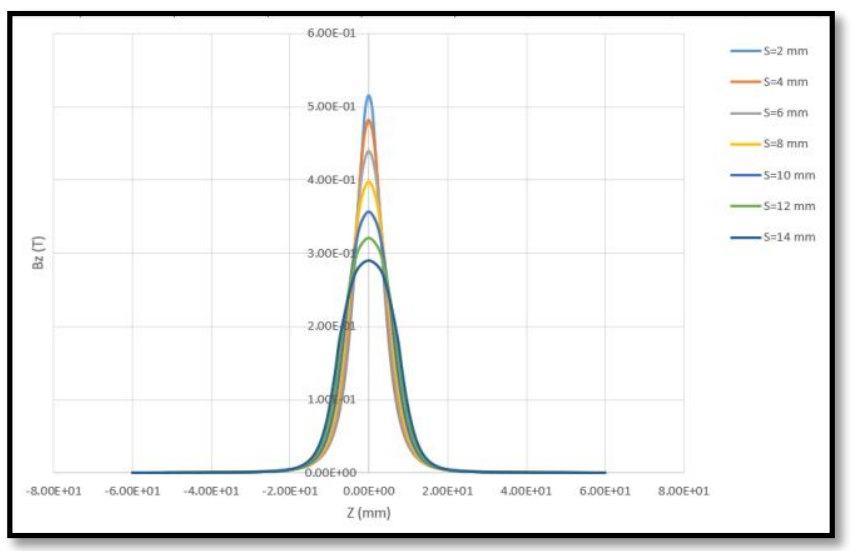

Figure 9. The axial magnetic flux density distribution (Bz) as function of the optical axis $\mathrm{z}$ for the proposed lens at different values $(S)$ and constant $(N I=4000 A-t)$ and $(D=6$ $\mathrm{mm})$.

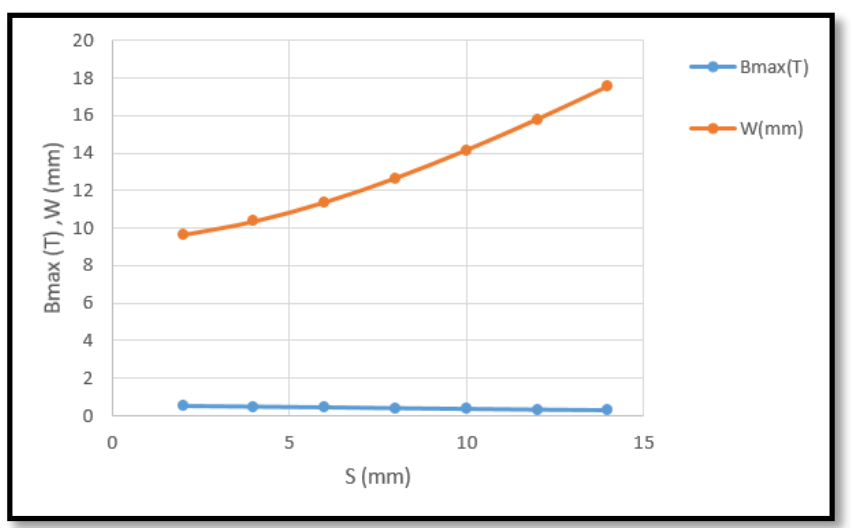

Figure 10. Show the Change in the maximum magnetic flux density $\left(\mathrm{B}_{\max }\right)$ and the half-width $(\mathrm{W})$ as function of (S) for the proposed magnetic lens.

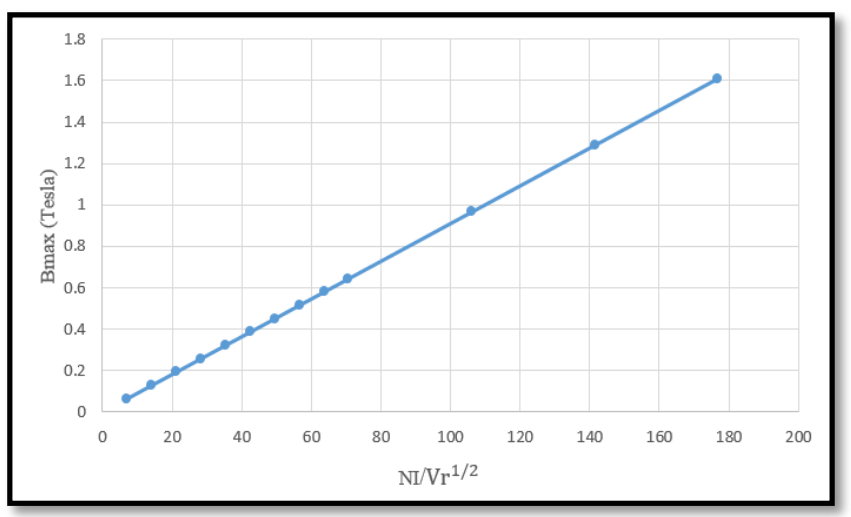

Figure 11. Shows the change in the maximum magnetic flux density $\left(\mathrm{B}_{\max }\right)$, a function of the excitation parameters (NI) at air gap width $(\mathrm{S}=2 \mathrm{~mm})$.
The trajectories of the electron beams of the symmetrical lens with different $\mathrm{S}$ are shown in Figure 12. From this figure, one can see that as $S$ is larger the paths of the electron beams are closer to the optical axis.

Figure 13 shows the values of the relative spherical and chromatic aberration coefficients as function of the $\mathrm{NI} / \mathrm{V}_{\mathrm{r}}^{1 / 2}$. Here, the values of the aberrations are all nearly less than 1 , which is very good values, and decreasing with increasing $\mathrm{NI} / \mathrm{V}_{\mathrm{r}}^{1 / 2}$.

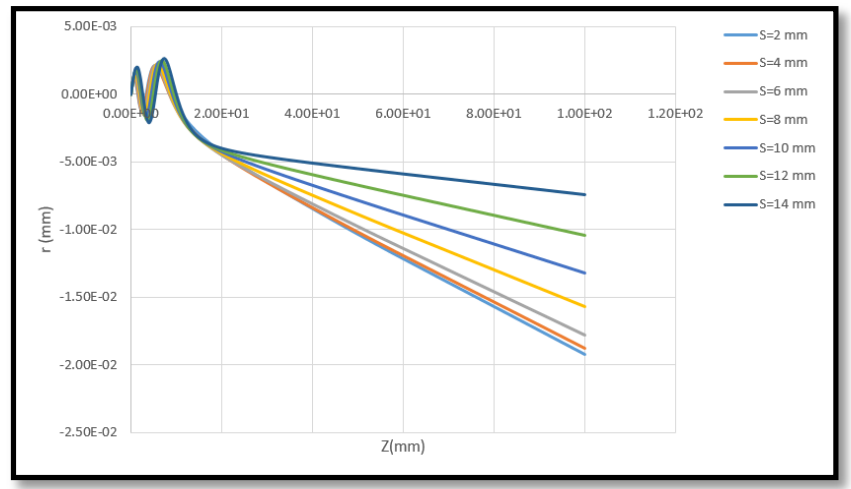

Figure 12. The trajectories of the electron beams at different values of the air gap width $(\mathrm{S})$ with constant axial hole diameter $(\mathrm{D}=6 \mathrm{~mm})$.

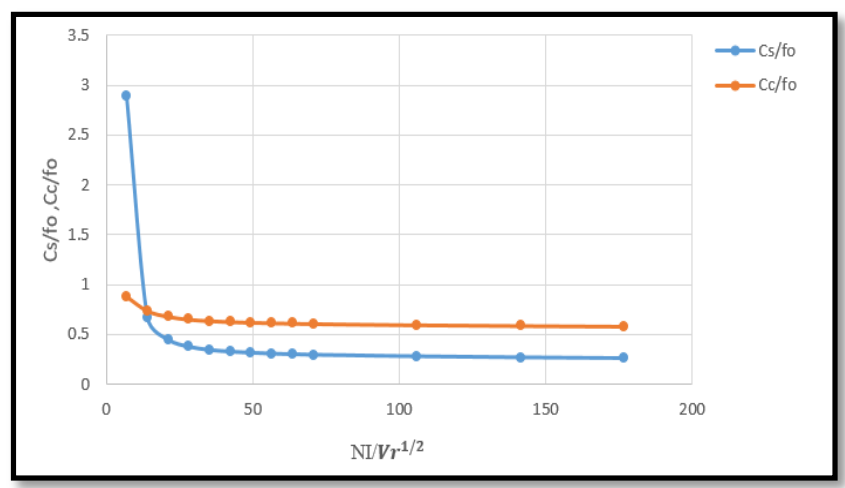

Figure 13. Shows the relationship of relative spherical and chromatic aberrations coefficients $\left(\mathrm{C}_{\mathrm{s}} / \mathrm{f}_{\mathrm{o}}\right)$ and $\left(\mathrm{C}_{\mathrm{c}} / \mathrm{f}_{\mathrm{o}}\right)$ respectively as function of excitation parameter $\left(\mathrm{NI} / \mathrm{Vr}^{1 / 2}\right.$ at fixed air holes $(\mathrm{S}=2 \mathrm{~mm})$.

Figure $14(\mathrm{a} \& \mathrm{~b})$ represents the relative spherical and chromatic aberrations coefficients (a) $\mathrm{C}_{\mathrm{s}} / \mathrm{f}_{\mathrm{o}}$ and (b) $\mathrm{C}_{\mathrm{c}} / \mathrm{f}_{\mathrm{o}}$ respectively, as function a function of acceleration voltages at constant excitation ( $\mathrm{NI}=4000$ A-turn) for different values of $\mathrm{S}$. From this figure, one can say that the values of both $\mathrm{C}_{\mathrm{s}} / \mathrm{f}_{\mathrm{o}}$ and $\mathrm{C}_{\mathrm{c}} / \mathrm{f}_{\mathrm{o}}$ are good and less than one for a wide range of the values of the air gap widths $\mathrm{S}$ and a wide range of accelerating voltages. These values of aberrations are increased with increasing the accelerating voltage which indicates that our proposed symmetrical magnetic lens is a good design. 


\section{Al-Nahrain Journal of Science}

ANJS, Vol.24 (1), March, 2021, pp. 30-38
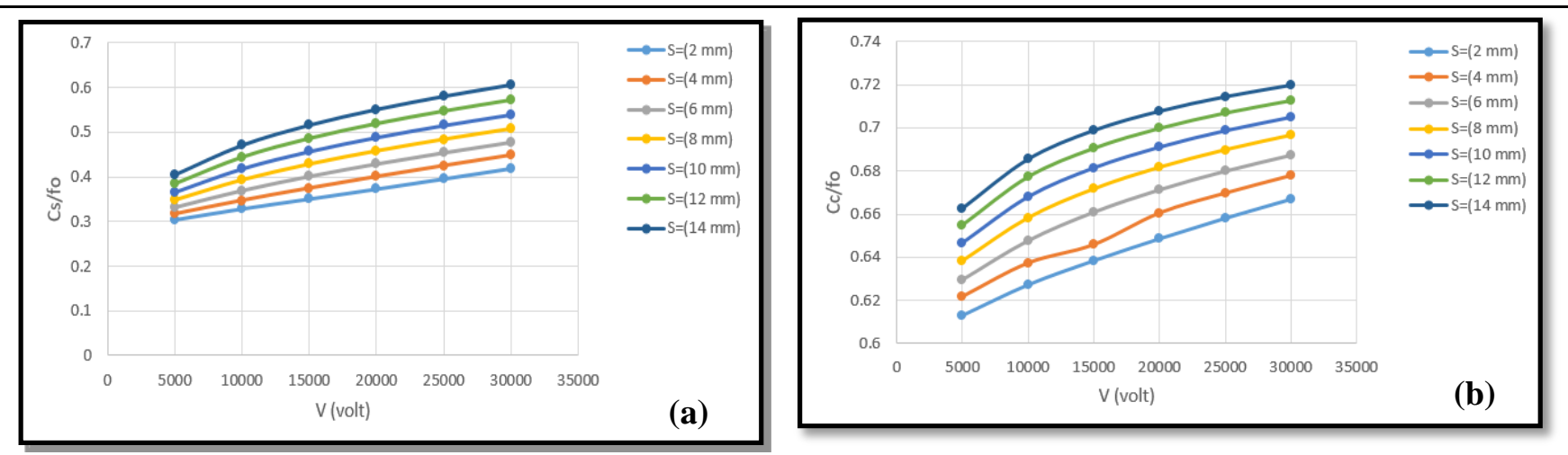

Figure $14(\mathbf{a} \& \mathbf{b})$. Shows the relationship of spherical and chromatic aberration coefficients $\left(\mathrm{C}_{\mathrm{S}} / \mathrm{f}_{\mathrm{o}}\right.$ and $\left.\mathrm{C}_{\mathrm{c}} / \mathrm{f}_{\mathrm{o}}\right)$ with accelerating voltage at constant $(\mathrm{NI}=4000 \mathrm{~A}-\mathrm{t}$ and $\mathrm{D}=6 \mathrm{~mm}$ ) for different values of $(\mathrm{S})$.

Table 2, summarized the results of the spherical and chromatic aberration coefficients as function of the values of $S$ and $f_{o}$.

Table 2. Adjusts the object-oriented optical property values to the air gap widths (S).

\begin{tabular}{|c|c|c|c|c|c||}
\hline $\mathbf{S}(\mathbf{m m})$ & $\mathbf{f}_{\mathbf{o}}(\mathbf{m m})$ & $\mathbf{C}_{\mathbf{s}}(\mathbf{m m})$ & $\mathbf{C}_{\mathbf{c}}(\mathbf{m m})$ & $\mathbf{C}_{\mathbf{s}} / \mathbf{f}_{\mathbf{o}}$ & $\mathbf{C}_{\mathbf{c}} / \mathbf{f}_{\mathbf{o}}$ \\
\hline \hline 2 & 2.64086 & 0.80210 & 1.61910 & 0.30372 & 0.61309 \\
\hline 4 & 2.58199 & 0.81729 & 1.60409 & 0.31653 & 0.62161 \\
\hline 6 & 2.59401 & 0.85998 & 1.63322 & 0.33152 & 0.62961 \\
\hline 8 & 2.65045 & 0.92317 & 1.69148 & 0.34831 & 0.63818 \\
\hline 10 & 2.73507 & 1.00146 & 1.76863 & 0.36615 & 0.64664 \\
\hline 12 & 2.83820 & 1.09248 & 1.85867 & 0.38492 & 0.65487 \\
\hline 14 & 2.95356 & 1.19423 & 1.95744 & 0.40433 & 0.66273 \\
\hline
\end{tabular}

\subsection{The effect of pole face thickness $(t)$ on the magnetic lens properties}

In order to study the effect of electrode face thickness (t) on the optical performance of the proposed lens, various values of $(t)(t=1,2,3,4,5,6 \mathrm{~mm})$ were tested with an air gap of $(S=6 \mathrm{~mm})$ and axial aperture diameter $(\mathrm{D}=6 \mathrm{~mm})$ while keeping the other engineering parameters constant. Figure 15 shows the effect of pole face thickness on the axial magnetic flux density distribution $\left(\mathrm{B}_{\mathrm{z}}\right)$, a function of the optical axis $\mathrm{z}$ of the proposed lens for different values of the pole face thickness $(t)$ at constant excitation $(\mathrm{NI}=4000$ A-turn). We note that the design in which the electrode thickness $(\mathrm{t}=3 \mathrm{~mm})$ has achieved the highest value of the axial magnetic field $\left(\mathrm{B}_{\max }=0.440361 \mathrm{~T}\right)$. Figure 16 illustrate the change in both the maximum value of the axial magnetic field and the mid-peak width of the field (W) as a function of the pole face thickness. We notice from the figure that increasing the thickness of the pole face results in an increase in the maximum value of the axial magnetic flux density $\left(B_{z}\right)$ to a certain value $t=3 \mathrm{~mm}$ and then the values of $B_{m a}$ decreases, which indicate the effect of the iron on the magnetic fields. This phenomenon became certain when the values of the half-field width (W) decreased when the values of $t$ increased to the same value $\mathrm{t}=3 \mathrm{~mm}$ and after that increased, where at the highest $\mathrm{B}_{\mathrm{ma}}$ the lowest value of $\mathrm{W}$. This is explained by the fact that reducing the thickness of the electrode face ( $t$ ) leads to reducing the area in which the magnetic field is spread through the lens pole, which increases the value of the magnetic field centered in the air gap.

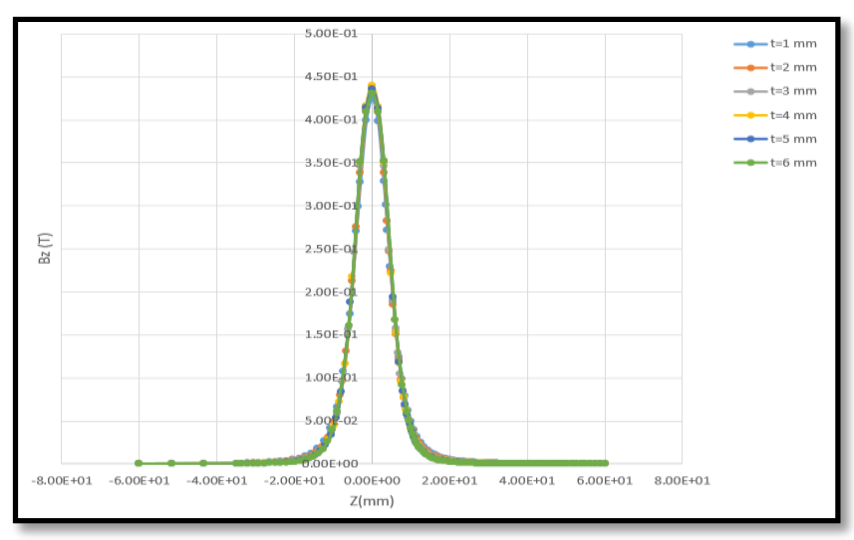

Figure 15. Shows the axial magnetic flux density distribution $(\mathrm{Bz})$ as function of the optical axis $\mathrm{z}$ for the proposed lens at ( $\mathrm{NI}=4000 \mathrm{~A}$-turn, $\mathrm{D}=6 \mathrm{~mm}$ and $\mathrm{S}=2 \mathrm{~mm}$ ) at variable values from the thickness of the electrode face $(\mathrm{t}=1,2,3,4,5$ and $6 \mathrm{~mm})$ 


\section{Al-Nahrain Journal of Science}

ANJS, Vol.24 (1), March, 2021, pp. 30-38
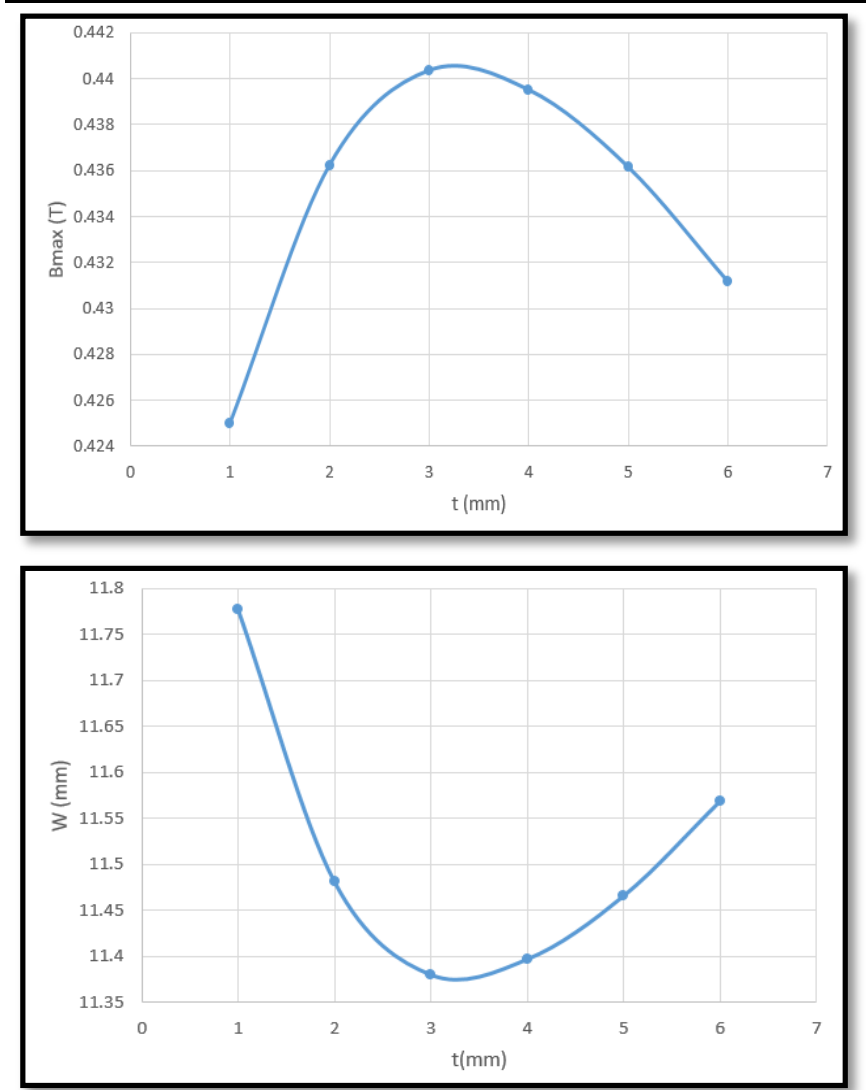

Figure 16. The maximum value of magnetic flux density $\left(B_{\max }\right)$, and the half-field $(\mathrm{W})$, versus the thickness of the electrode face $(\mathrm{t})$ with $(\mathrm{S}=2 \mathrm{~mm}$ and $\mathrm{D}=6 \mathrm{~mm})$.

From Figure 17, one can see the linear relation between the change in the maximum magnetic flux density $\left(\mathrm{B}_{\max }\right)$, and the excitation parameters $\left(\mathrm{NI} / \mathrm{V}_{\mathrm{r}}^{1 / 2}\right)$ at thickness $(\mathrm{t}=3$ $\mathrm{mm}$ ). This linear relationship indicates the readability of the proposed lens designed.

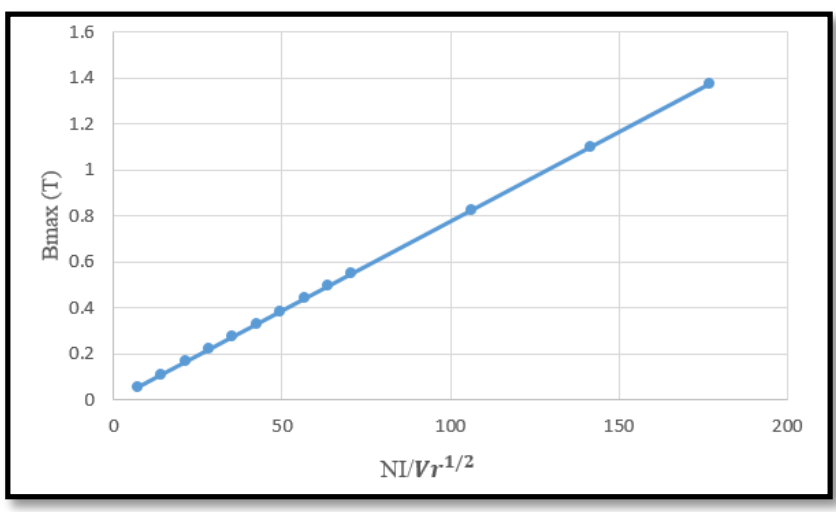

Figure 17. Shows the change of magnetic flux density $\left(B_{\max }\right)$ for different values of $\mathrm{NI} / \mathrm{V}_{\mathrm{r}}^{1 / 2}$ at a fixed accelerating voltage $(\mathrm{V}=5000 \mathrm{~V})$ and fixed $(\mathrm{t}=3 \mathrm{~mm})$.

The trajectories of the electron beams of the symmetrical magnetic lens with different $t$ are shown in Figure 18. The behavior of the electron paths in this case is different from the other parameters $\mathrm{D}$ and $\mathrm{S}$. From this figure, one can see that as $t$ is larger the paths of the electron beams are closer to the optical axis.

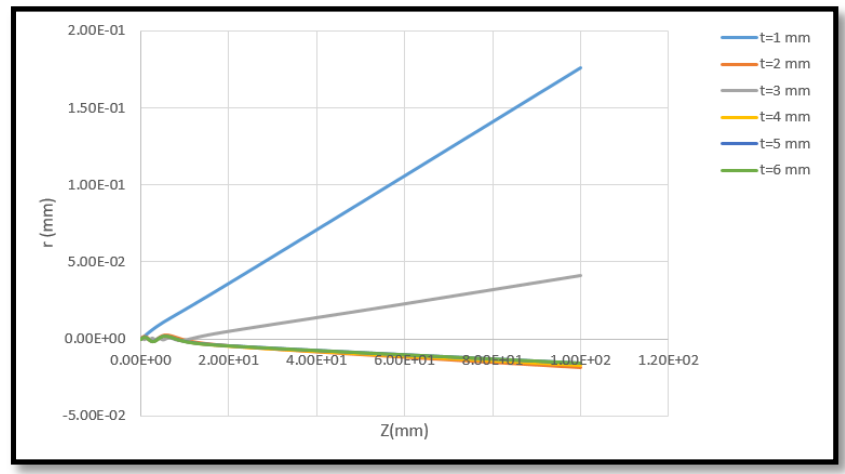

Figure 18. The trajectories of the electron beams at different values of the pole face thickness $(t)$ with constant $(\mathrm{D}=6 \mathrm{~mm}$ and $\mathrm{S}=2 \mathrm{~mm}$ ).

Figure 19 shows the values of the relative spherical and chromatic aberration coefficients as function of the $\mathrm{NI} / V_{r}^{1 / 2}$. Here, the values of the aberrations are all nearly less than 1 , which is very good values, and decreasing with increasing $\mathrm{NI} / V_{r}^{1 / 2}$.

Figure $20(\mathrm{a} \& \mathrm{~b})$ represents the relative spherical and chromatic aberrations coefficients (a) $\mathrm{C}_{\mathrm{s}} / \mathrm{f}_{\mathrm{o}}$ and (b) $\mathrm{C}_{\mathrm{c}} / \mathrm{f}_{\mathrm{o}}$ respectively, as function a function of acceleration voltages at constant excitation $(\mathrm{NI}=4000 \mathrm{~A}-\mathrm{t})$ for at $\mathrm{t}=3$ $\mathrm{mm}$. From this figure, one can say that the both $\mathrm{C}_{\mathrm{s}} / \mathrm{f}_{\mathrm{o}}$ and $\mathrm{C}_{\mathrm{c}} / \mathrm{f}_{\mathrm{o}}$ are good and less than one for a wide range of the accelerating voltages. The values of spherical aberrations is increased with increasing the accelerating voltage while the chromatic aberrations increases slowly and decreased rapidly at accelerating voltage equals to $30000 \mathrm{~V}$.

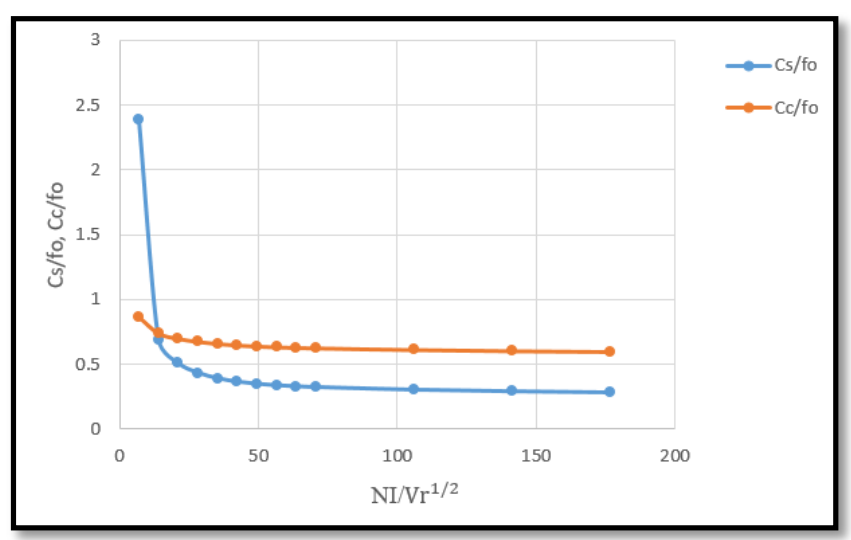

Figure 19. Shows the spherical and chromatic aberration coefficients $\left(\mathrm{C}_{\mathrm{s}} / \mathrm{f}_{\mathrm{o}}\right.$ and $\left.\mathrm{C}_{\mathrm{c}} / \mathrm{f}_{\mathrm{o}}\right)$ as function of accelerating voltage at fixed $(\mathrm{V}=5000 \mathrm{~V}$ and $\mathrm{t}=3 \mathrm{~mm})$. 


\section{Al-Nahrain Journal of Science}

ANJS, Vol.24 (1), March, 2021, pp. 30-38
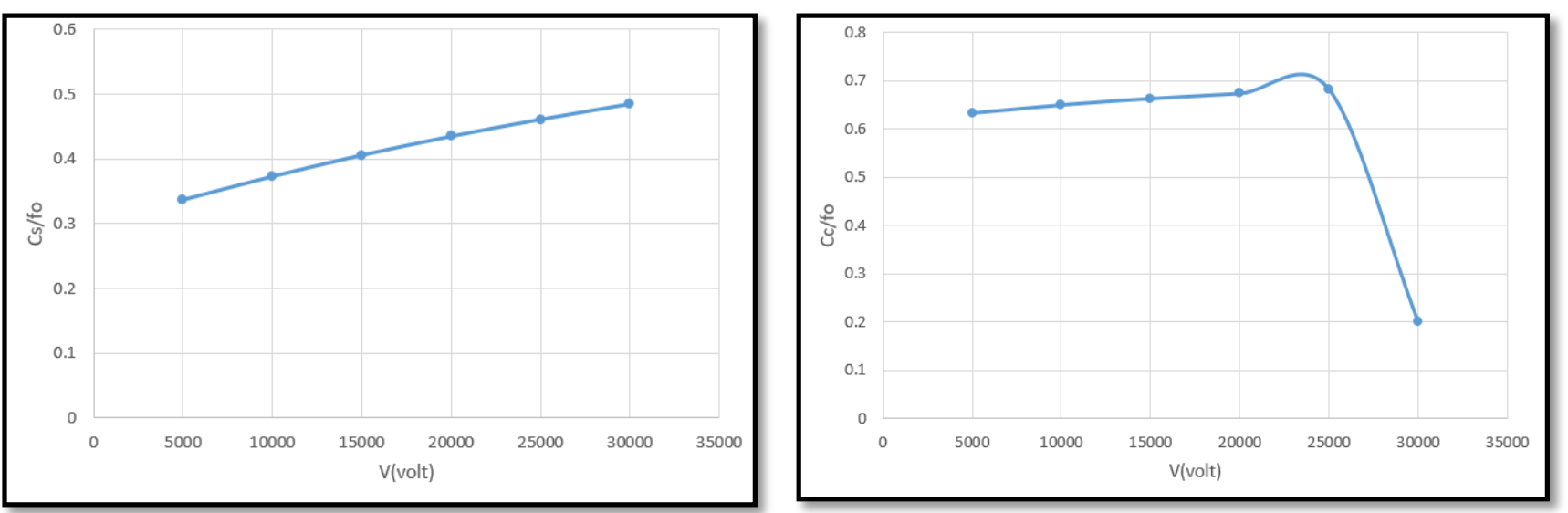

Figure 20. Shows the relative spherical and chromatic aberration coefficients $\left(\mathrm{C}_{\mathrm{s}} / \mathrm{f}_{\mathrm{o}}\right.$ and $\left.\mathrm{C}_{\mathrm{c}} / \mathrm{f}_{\mathrm{o}}\right)$ as function of the accelerating voltages at constant $(\mathrm{NI}=4000 \mathrm{~A}-\mathrm{t}$ and $\mathrm{t}=3 \mathrm{~mm})$.

Table 3, summarized the results of the spherical and chromatic aberration coefficients as function of the values of $t$ and $f_{o}$.

Table 3. Adjusts the object-oriented optical property values to the Pole face thickness (t).

\begin{tabular}{|c|c|c|c|c|c||}
\hline \hline $\mathbf{t}(\mathbf{m m})$ & $\mathbf{f}_{\mathbf{0}}(\mathbf{m m})$ & $\mathbf{C}_{\mathbf{s}}(\mathbf{m m})$ & $\mathbf{C}_{\mathbf{c}}(\mathbf{m m})$ & $\mathbf{C}_{\mathbf{s}} / \mathbf{f}_{\mathbf{o}}$ & $\mathbf{C}_{\mathbf{c}} \mathbf{f}_{\mathbf{o}}$ \\
\hline \hline 1 & 2.89567 & 0.90648 & 1.79415 & 0.31304 & 0.61959 \\
\hline 2 & 2.71272 & 0.87625 & 1.69479 & 0.32301 & 0.62475 \\
\hline 3 & 2.59401 & 0.85998 & 1.63322 & 0.33152 & 0.62961 \\
\hline 4 & 2.54454 & 0.85884 & 1.61208 & 0.33752 & 0.63354 \\
\hline 5 & 2.52532 & 0.85003 & 1.60274 & 0.3366 & 0.63466 \\
\hline 6 & 2.51109 & 0.8377 & 1.59105 & 0.3336 & 0.6336 \\
\hline
\end{tabular}

\section{Conclusions}

1- As the axial aperture diameter values (D) decrease for the lens, the maximum value of the axial magnetic flux density (B max) increases, and this is followed by a reduction in half width $(\mathrm{W})$.

2- As the values of the axial aperture diameter (D) decrease, the values of the objective dimensional dimension $\left(\mathrm{f}_{\mathrm{o}}\right)$ and the aberration coefficients $\left(\mathrm{C}_{\mathrm{s}}, \mathrm{C}_{\mathrm{c}}\right)$ decrease and the lens becomes good optical object properties due to a decrease in the width of half of the magnetic field (W).

3- Use high-resolution (EOD) software to acquire magnetic lenses with strong optical properties.

4- The maximum value of the axial magnetic flux density $\left(\mathrm{B}_{\max }\right)$, increases as the Air gap width values (S) decrease for the lens, and this is accompanied by a decrease in half width (W).

5- The values of the objective dimensional dimension $\left(\mathrm{f}_{\mathrm{o}}\right)$ and the aberration coefficients $\left(\mathrm{C}_{\mathrm{s}}, \mathrm{C}_{\mathrm{c}}\right)$ decrease as the values of the Air gap width (S) decrease and the lens becomes of good optical object properties due to a decrease in the width of half of the magnetic field (W).

6- The maximum value of the axial magnetic flux density $\left(B_{\max }\right)$, increases as the thickness of the pole face $(t)$ increases, accompanied by a decrease in the width of the half $(\mathrm{W})$ and there is an optimal value at which the best magnetic properties and the highest value of the magnetic spill are achieved and the lowest value of the axial field strength bandwidth was at the value of the pole face thickness equal to ( $3 \mathrm{~mm}, 4 \mathrm{~mm}$ ).

7- Through the study of the properties of the proposed magnetic lens, the best lens with optimal properties was deduced, that is, the air gap width $(\mathrm{S}=2 \mathrm{~mm})$, the diameter of the electrode aperture $(\mathrm{D}=6 \mathrm{~mm})$ and the thickness of the electrode face $(t=3 \mathrm{~mm})$ at fixed values for both voltage and excitation (NI=4000 A-turn, $\mathrm{V}=5000$ volt).

\section{References}

[1] Knoll M. and Ruska E. Z., physik.78, 318, 1932.

[2] Von Aedenne M. and Physik Z., 109, 553-572, 1938.

[3] Al-Khashab M. A and Al-Hialey R. W., "The effect of geometrical shape and position of the coil on optical performance for asymmetrical magnetic lens", Rafidain journal of science, 24(2), 91-100, 2013.

[4] Egerton R. F., "Physical principles of electron microscopy an introduction to TEM, SEM, and AEM", Wiley, Canada, 2007.

[5] Humphries S. Jr., "Principle of charged particle acceleration", Wiley, New York, 1999. 


\section{Al-Nahrain Journal of Science}

ANJS, Vol.24 (1), March, 2021, pp. 30-38

[6] Al-Khashab M. A., Ahmed A. A. H., "Some approaches to the projector lens pole piece geometry and their effect on magnetic flux lines", Dirasat, Pure Sci, 31(1), 22-29, 2004.

[7] Alamir A. S. A., "The chromatic aberration of magnetic lenses with a field distribution in the form of an inverse power low $(\mathrm{B}(\mathrm{z}) \propto \mathrm{z}-\mathrm{n})$ ", Optik, 115(5), 227-231, 2004.

[8] Alaa A. H. Ahmed, "The Effect of Coil Geometry and Magnetic Circuit on the Flux Lines Trajectory of the Magnetic Lenses", Rafidain journal of science, 16, 95$108,2005$.

[9] Abdullah E. Al-Abdullah and Al-Khashab M. A., "The magnetization of the single pole piece magnetic electron lens using different coil models", Rafidain journal of science 17, 37-46, 2006.

[10] Majid R Chalab, "Effect of pole piece shape on properties of the symmetrical objective magnetic lenses", University of Thi-Qar Journal, 4(4), 1-16, 2009.

[11] Al-Khashab M. A. and Hujazie N. S., "Design of the Objective Magnetic and Electrostatic Lenses for Low Beam Energies", Dirasat, Pure Sciences, 37(2), 2010.

[12] Al-Batat A. H. H. and Al-Rubaye Z. H. K., "Simulation of Magnetic Electron Lenses", Journal of Kerbala University, 10(3), 217-227, 2012.

[13] Alaa A. Ahmed, "The Effect of Compound Magnetic-Electrostatic Lenses Insulation on its Optical Properties", Rafidain Journal of Science, 25(6), 70-79, 2014.

[14] Hujazie N. S. A. and Hussain M. A., "Design Software of the Double Condenser Magnetic Lens System in a Scanning Electron Microscope", Iraqi Journal of Science, 55(A4), 1563-1571, 2014.

[15] Roaa T. Abdulla, "Study the Optical Properties of Iron- Free Magnetic Lens", Journal of Al Nahrain University (science), 18(2), 79-82, June, 2015.

[16] El-Shahat S. S., Al Amir A. S. A. and Hassan G. S., "Studies on the effect of pole piece shape for saturated single pole magnetic lens", Proceedings of the $1^{\text {st }}$ International Conference on New Horizons in Basic and Applied Science, Hurghada-Egypt, 1(1), 290-298, 2013.

[17] Talib Mohsen Abbas and Qutaiba Ahmed Sahi, "Design and Study of the Optical Properties of Electromagnetic Lenses Dual-polar analog using the program (EOD)", Journal of University of Babylon for Pure and applied Science, 25(6), 1991-1997, 2017.

[18] Numan N. H., "Theoretical Study of Geometrical Properties and Aberrations in Doublet Magnet Lenses", Journal of University of Babylon for Engineering Sciences, 26(8),178-187, 2018.

[19] Al-Shamma M. T. and Al-Khashab M. A., "Improvement of the Optical Performance of the Geometrical Parameters of Snorkel Magnetic Lens", Rafidain journal of science, 28(1E), 85-97, 2019.
[20] Bohumila Lencová and Jakub Zlámalb, "A new program for the design of electron microscopes", Physics Procedia, Proceedings of the Seventh International Conference on Charged Particle Optics, 1, 315-324, 2008. 